\title{
FROM SURVIVAL TO LIVELIHOOD IN MOZAMBIQUE
}

Reginald Herbold Green and Maria Mavie

Time past and time future

Are both - perhaps - contained in time present.

.... all time is irredeemable.

- T. S. Eliot

We must look our mistakes squarely in the face

Lest we fall into repeating them.

- Rui Baltasar Santos

Sometime Finance Minister, Mozambique

\section{INTRODUCTION}

Disasters can be usefully divided into two categories: natural, in Southern Africa droughts, floods and severe storms; and man-made, characterized by violent civil disorder and war. It is perhaps convenient to use Mozambican terminology of 'calamities' for the first and 'catastrophes' for the second. For both calamities and catastrophes, the objectives of disaster relief are survival of afflicted populations and rehabilitation of their livelihoods. The first is a prior condition - the livelihoods of the over 1,500,000 Mozambicans dead because of the 1980-1992 war can nolonger be rehabilitated. But survival is notenough. Lost assets (whether blown up bridges or droughtdead cattle) do not restore themselves; the speed of dislocated households' ability to rehabilitate their livelihoods is significantly dependent on appropriate supporting measures and resource allocations; restoring human capacity and building service and market access is a complex, tedious and expensive process (cf. UNICEF 1989 and 1993 and Green 1994).

Calamities on their own require substantial rehabilitation, as a phase conceptually between survivalsupport and medium-term development strategy implementation, albeit practically overlapping both (see papers by Seaman, Davies and Buchanan-Smith / Maxwell in this Bulletin). However, the need to make reconstruction and rehabilitation central to medium term macro-economic food security and poverty reduction strategies arises more particularly in the case of catastrophes or complex calamity/catastrophe mixes. In such cases, peace and rain create the necessary preconditions for recovery, but are not sufficient conditions for achieving it.

Unfortunately, there is both next to no historic experience with post war reconstruction and livelihood rehabilitation as a strategic priority in SSA, and very little conceptual attention to it by donors, most NGOs, SSA governments (with the notable exception of Mozambique) or, until quite recently, academic and practitioner researchers and analy tical writers: it has remained an 'unserviced limbo' in development.

This article sketches the nature of rehabilitation reconstruction requirements after catastrophes in SSA and illustrates the approach by looking at the country which has placed the highest priority on the process - Mozambique.

Mozambique has suffered under war since 1964 when the liberation war against Portugal began. However, following independence and until 1981, the areas of combat were limited, as were its levels, and a reconstruction and recovery dynamic, plus substantial ground-breaking in human/human investment services, had been established. This $d y-$ namic was reversed by South African-activated and (until 1991) dominated destabilization, carried out by Renamo over 1982-1992 (see UNICEF 1989).

The cumulative loss of output by 1992 exceeded $\$ 20,000$ million or ten times actual 1992 output (projected from UNICEF 1989 as are most other numerical estimates in this section). The loss of life primarily from the interaction of collapsed rural health services, disrupted food production and blocked transport routes - was of the order of $1,500,000$, albeit Under-5 mortality had fallen from a 1986 estimate of over 325 per 1,000 live births to under 300 .

Over half the population (probably 12,500,000 in Mozambique and 1,500,000 to 2,000,000 refugees versus a counterfactual $16,500,000$ in Mozambique 
without war) had been forced out of production. $1,500,000$ to $2,000,000$ were international refugees; $2,000,000$ internal refugees in camps or resettlement schemes; 2,000,000-plus dislocated, but not in formal camps (and, as a result, often worse off than those who were) and over 1,000,000 nominally in home areas but in fact lurking around ruined villages, scrabbling out a little food by day and hiding by night, for a total of the order of $7,000,000$. (cf. Mozambique 1991, 1992.)

Absolute poverty in 1992 afflicted over 60 per cent of all Mozambicans - over 50 per cent urban and 70 per cent of rural households (Mozambique 1991 1992 with the urban figure confirmed by 1992-1994 Household Urban Budget Studies by National Directorate of Statistics). The government - as a result of the disastrously eroded revenue base and high war expenditure - was also absolutely poor, with perhaps 70 per cent of combined recurrent, capital and emergency (survival support) spending externally financed, programmed and especially in the last category - operated (internal NDP estimates, broadly consistent with those of the World Bank).

The weakness of state financial, physical and personnel capacity had frustrated donors, who in response had created a host of expatriate-run enclaves within the state system, plus a host of overlapping parallel donor government and external NGO delivery systems, which, in practice, fragmented and decapacitated the state further (cf. Hanlon 1991).

From 1988, substantial elements in Mozambique's leadership and state institutions - including the President, Prime Minister, Planning, Finance and Health - began to focus on and articulate poverty reduction as a strategic economic and production as well as socio-political and welfare (or ill-fare alleviation) goal (Mozambique 1991). The production enabling aspects by 1990 had come to focus on post-war reconstruction and livelihood rehabilitation for and by war dislocated households (Mozambique 1992a, 1992b).

\section{REHABILITATION AND RECONSTRUCTION'}

What is needed varies with context. One set of diversities relates to crisis in terms of responses needed and for how long:

a Projectibility of Recurrence - e.g. droughts do recur and are cyclical (albeit their periodicity may vary) ${ }^{2}$ but wars (and their duration) much less so;

b Length of Crisis Period - e.g. floods (in Southern Africa) rarely recur in successive years except in a few river deltas, droughts rarely run to more than three disaster years in a row (but two is quite common); wars are not predictable;

c Bread th/Depth of Decapitalization - war is clearly worst, flood usually second (albeit over small areas in the case of Southern Africa), drought in pastoral economies variable (largely depending on duration and severity) and drought for field or tree crops;

d Whether Afflicted Persons Have to Move which greatly exacerbates (and may prevent) rehabilitation - worst for war, preventable with adequate, early response in the case of drought. ${ }^{3}$

e Cumulative Impact (of repetitive crises) - probably most severe in the case of pastoralists (or agropastoralists) in both drought and war conditions.

Another set of diversities relates to household patterns: tree crop dominant; field crop dominant; pastoral dominant; wage income (agro or other) significant. In general, the first few normally show a rising order of impact and of barriers to rehabilitation in the case of calamities, while the last is very contextual (e.g. seasonal agricultural wages are likely to be devastated; public works wage incomes may actually rise, e.g. Botswana).

In practice, calamity afflicted households, who had to leave home areas, may need transport and are likely to need tools and basic household goods, as well as seeds and food, up to the first harvest. If they have been 'away' for over a year they may need

\footnotetext{
1 Reconstruction relates to physical and social (e.g. health, education) infrastructure and is particularly relevant in post-war situations but also after floods. Rehabilitation relates to household livelihoods and is equally relevant to calamities and catastrophes.

2 For example, since 1974/75 Eastern and Southern Africa has apparently had five year cycles: five good, five bad. Both are relative - an average or moderately good year is possible in a bad cycle and a moderately poor or average in a good. Except in very extreme
}

cases some countries and some districts in countries do not conform to the pattern. For example, even in 1991/92 Tanzania was - overall - not severely affected nor were the two Northernmost Provinces of Mozambique nor some districts in three others even though nationally over half of normal grain output was lost.

${ }^{3}$ Vide 1950-1994 Tanzania, 1975-1980 Mozambique versus 1982-1992 Mozambique and Angola. 
clearing tools and - depending on return timing food support for up to 15 months. A rapid succession of calamities has a cumulative impact and may require additional replacement working capital injection. This is true especially, but not only, for pastoralists. ${ }^{4}$

Catastrophe afflicted households, on the other hand, need a broader and longer term 'enabling' programme. It includes physical infrastructure, social infrastructure/basic services and market-access rehabilitation. Ideally, it would include works employment programmes on an enhanced basis for up to five years. ${ }^{5}$

Mozambique has both kinds of household. However, given the numbers involved, a central problem concerns the process of 'going home'.

Baseline data - necessarily vague before return - are needed to programme on an intelligent, articulated basis.

- How many people have fled? From where? (Not all empty areas were ever populated, e.g. half of Mozambique was, for good reasons, very sparsely peopled in 1980 before the war, as shown on 1980 Census population distribution maps.)

- To where? (Usually home district and often same land, cf. UNOHAC 1994 Mozambique mapping of actual and planned return levels.)

- How do nominally resettled view themselves? (Often as dislocated and wishing to return - internal memoranda of National Planning Directorate based on fragmentary observations.)

- What present resources? (Some refugees have tools and food stocks from farming in exile.)

- With what perceived needs? (Transit camps and central land allocation rarely came high on their lists.)

\footnotetext{
4 Most pastoral communities have coping mechanisms involving loans in kind, repaid in kind, to hard-hit households. These erode when crises are long lasting or quickly repeated and especially if a very high per cent of families are seriously afflicted and total herd loss percentages very high, e.g. much of Central and Southern, though not North-Western or North-Eastern Somalia, in 1993 (cf. Green 1993c).

${ }^{5}$ The purpose is not simply - or even necessarily primarily - to buy food. Households have cash needs - tools, seed, salt-sugar-tea/ coffee, cooking oil, cloth, school and health service costs. If no other
}

- How fast and how do they plan to return? (All at once as complete households is an unlikely answer.)

- How much farm and home reconstruction and repair is needed? (This affects tools needed, duration of food requirement - as working capital - and how much time will be available to take up public works wage-earning opportunities.)

Mozambique has made efforts to estimate these parameters from both the district of origin and present location ends, an exercise beginning in 1990 and now somewhat overtaken by events (probably over 5,000,000 of 7,000,000 catastrophe-impacted are back at work on home farms).

Return processes are usually phased. A common model includes: community scouts to report on situation (including security); pioneers (usually adult males) to start clearing and rebuilding; additional family members returning - some for part of the year; full return. This works well with minimum assistance when it can be built up over several years, is to a nearby area and is by people with some exile livelihood (as illustrated in Angoche District of Tete Province since 1988/89). For further away districts, with no initial 'welcoming' group and low or nil food reserves in asylum areas, it is much harder.

This pattern implies that camp-based refugees/dislocated persons will need to remain on the camp food roster until the fourth and final phase. Pioneers will return to collect food - witness the otherwise bemusingly high levels of two way traffic among Malawi and Sofala and Zambesia in 1993 reported by several observers. The refugee camp model is supposed to be whole family return with limited food support for six months or less. In rehabilitation/ reconstruction cases, this is quite simply not realistic. Out-in-out patterns unfortunately often lead to perceptions of fraud. ${ }^{6}$

The strategy set out is designed to enable disaster afflicted households to return home and to restore

source of cash is available, they will use food as their cash crop even if the result is inadequate nutrition. The five year period assumes gradual return home over three years.

\footnotetext{
" Many refugee agency staff often appear to view those they are supposed to serve as inherently criminal in nature, with "cheating UNHCR" their main aim. This is, perhaps, not a very productive approach and certainly not one conducive to working out support for phased return with either home district support or regular returns to camp for food.
} 
their livelihoods within parameters informed by their own goals/needs. The intent is to coordinate and to manage services (whether 'transport ${ }^{\prime 7}$ home or operational support to mediating disputes within land allocation by 'elders' or 'chiefs') not to manage returnees.

The approach of enabling as opposed to managing / directing has been stressed by Mozambique's Planning Directorate. Somewhat to the Directorate's surprise, most donors and many refugee related NGOs have criticized it for not specifying what returnees 'should do'. Provincial and district officials have been more attuned to such an approach perhaps because it reduces the work load on them, especially as to issuing and trying to effectuate instructions unlikely to be welcomed or followed. Orders to returnees would be likely to be objectively wrong as well as unwelcome and there are rather better things for a weak post catastrophe government to do than to issue orders which are perceived as foolish and objectionable and clearly cannot be enforced.

\section{A PROGRAMME CHECK LIST}

The key elements in household return and livelihood rehabilitation programmes appear to include:

a transport home: Though, unless the distance is over $200 \mathrm{~km}$, this may be less important than usually supposed, especially for early pathfinder/pioneer phases. In practice most dislocated persons return on their own (90 per cent in Mozambique to date, judging by UNOHAC and UNHCR internal estimates);

b food until harvest: Clearing, building, preparing land, planting, tilling, harvesting are hard work and there are no instant crops and often few surviving feral food sources. Transit or holding camps are not a large part of the answer because they delay getting back to work on the land;

c seeds/tools/draught animals/small-stock and poultry/core livestock herds (for pastoralists);

d other inputs: Building materials, fertiliser, pesticides, while sometimes cited, appear to be low priority in context of very scarce resources. Tools to clear and to build, of course, are in category ' $c$ ' and are a priority;

e secure access to and use rights over land: State allocation is likely to be impracticable. ${ }^{8}$ Use of pre crisis, neo-traditional system plus dispute resolution mechanism is probably usually workable. Abandoned large farms will be taken over, unless the owner gets back in time to have a physical presence. Attempts to prevent this are likely to be very conflictual, politically imprudent in contexts of democratic election and minimally effective. This point is put very forcibly by many Mozambican District/ Provincial officials and some Provincial Governors. 'You will start a real civil war' commented one (internal NDP resumé of land issues workshop);

f restoration of Health-Water-Education: (Basic human investment) both to 'enable', through time saving and health improving, and because - together with physical security - these are at the top of the displaced households' priority lists of what the state should provide;

g restoration of Physical Infrastructure: Buildings for basic human services as well as transport, necessary government and community buildings including housing for teachers, health personnel, agricultural extension agents, and administrators;

h Iabour intensive works employment: timed to peak at low agricultural labour requirement months, with mechanisms to ensure female access (both to get the physical infrastructure rebuilding done and to enhance household cash incomes in initial years);

i restoration of market access: is crucial to family small farming households. Without it they cannot produce for sale or work their way out of absolute poverty. Rural traders/transporters are central, to buy produce, to sell consumer goods, tools, construction materials, and to provide transport from Provincial Capitals/large district towns to where family farming households live. They need access to lorries, working capital, basic goods for rural commercial network as a livelihood rehabilitation priority, not so much in respect to trader livelihoods

households usually know better than governments or NGOs what pattern of return will best fit their needs and capacities

8 The concept of delaying return for land demarcation and certificate issuing - while sometimes proposed - is surreal. 
as in respect to those of returnees. If, as in Mozambique, traders are decapitalized and lack access to term credit, ensuring enterprise (not government) provision of commercial hire-purchase facilities is a priority for state action.

\section{SOME OBSTACLES}

Once the barrier is overcome of acceptance of rehabilitation as a basic strategy, a series of specific weaknesses emerge. In Mozambique, these have included:

a strategic capacity - weak field level knowledge from which to aggregate and to analyse; detailed conceptualization; ability to articulate to link concepts and field data via programmes and interaction vertically and horizontally within and beyond government.

b provincial and district capacity - limited habit of asking people and listening to answers; low numbers of technical/professional personnel even at Provincial (near absence at District) level; lack of any recent prior articulated planning - implementation experience at these levels; absence of any bureaucratic system to routinize the 90 per cent of operations which are (should be) routine; absence of formal means to secure user feedback or to receive and respond to local social sector initiatives;

c understanding of family farming household situations, e.g. typical hands to mouths ratios; intra household (gender and age) divisions of labour-incomeexpenditure; present and short term potential sources of income including household self provisioning and off farm labour as well as cash crop (i.e. crops produced to sell whatever their use by the buyer); actual access to and own priority for enhanced access to basic services and to markets.

d donor past and ongoing decapacitation of government and domestic social sector, i.e. parallel, non-coordinated, non-accountable systems which may raise instant capacity in crisis situations but are contradictory with either national or local domestic capacity rehabilitation - or domestic programme 'ownership';

e donor response lags including desire for a normal project appraisal format and for quantitative micromacro linkage modelling when the former is inappropriate as well as impossible and the latter necessarily approximate ex ante. ${ }^{10}$

The result of these weaknesses is a set of lags over 1988-1994 - extreme, even by Mozambican standards:

a 1988-90 design of a priority district rehabilitation programme, 'remodelled' by donors into a narrow front, long term strategic approach logically following after rehabilitation;

b July 1992 first official draft National Reconstruction Programme (PRN), presented to donors December 1992;

C 1992-93-Provincial Planning exercisebuilt around PRN ;

d December 1993 - Proposal of some elements (out of conceptual context) of PRN to donors by World Bank.

To date, in Mozambique, the results in the budget and in the field are distressingly modest: initial mine lifting programmes; somewhat more rehabilitation focus in health, perhaps education, water, agriculture programming; a clear government reaching out to the domestic social sector as a co-operating partner (e.g. President Chissano's 1993 speech on occasion of Centennial Celebrations of Diocese of Limbos and Mozambique 1994); partial rehabilitation of provincial planning capacity; studies toward a hire purchase enterprise; continued CENE/DPCCN food provision to returnees and some parallel UNHCR input; a change in the climate of discussion in some

\footnotetext{
${ }^{9}$ The issue is not one of intent. The point is that fragmentation, noncoordination and multiple authoritarian/clientalist systems from external bodies to weak, de facto cap tive Mozambican units prevent state accountability (including the accounting as well as the broader sense) and enabling capacity growth even more than they limit its ability to coerce or to intervene operationally and cripple social sector-state relations as well as distorting their external relations. They are - as their builders fail to realise - not a contribution to building an accountable-selective-limited role on any blueprint let alone one responsive to Mozambicans or appropriate to the Mozambican context.
}

10 Oddly the National Reconstruction Programme (Mozambique, $1992 \mathrm{~b}$ ) is the only one in Mozambique which does do this even approximately. It has order of magnitude projections for GDP, linkages to other sectors, fiscal sources/uses, external balance as e.g. - the rolling, large scale Public Priority Investment Project list does not. Why it - and not PTIP - should be challenged on this ground is, therefore, an interesting question. 
ministries and the Planning Commission toward perceiving sector familial livelihood rehabilitation as socially and economically central; avoidance of massive interference with returnee self allocation of home area land for resettlement and of refugee / dislocated person camp food cut-offs which would be consistent with their rules but not with returnee patterns of phased moves home; and at least putting 'the land question' on the agenda in a way limiting Land Commission/Agriculture allocation of occupied sector familial land to outsiders (external or domestic).

\section{ISSUES OF APPROACH: ITERATIVE FLEXIBILITY}

One way to tackle these problems is by iterative flexibility. Flexibility based on built-in monitoring and review as a management tool is likely to be important to livelihood rehabilitation. Initial data especially on returnee numbers, intentions, capacities and needs - will be, at best, roughly correct overall and in direction, with numerous gaps and errors of detail, identifiable only when/if the programme is operational. The type of precise data formulation and analysis suitable for a large hydroelectric project is neither possible nor suitable. Rolling programme adjustment (e.g. re prioritizing which bits of infrastructure to repair/add or what extension service crop and technique specific content is appropriate), if built in advance can be practicable and low cost (as it assuredly is not for a large dam). Decentralization (to a level allowing asking programme users and listening to their answers) is a necessary component of iterative flexibility.

Loans, grants, privatization and all that are, or should be, pragmatic not ideological questions. That is a key matter of approach. Ideological debates lead to impasses, while dialogue on operational, least inefficient ways and means often lead to working agreement on what is to be done.

Initial provision of seeds, tools, food until harvest etc., should be free. There is a normative case, but the bottom line is that scores of thousands of small (say $\$ 100$ ), three to five year, low interest loans are

\footnotetext{
${ }^{11}$ Nominally this is the Mozambique pattern and one many retailers (local trader/transporters) welcome. In fact, the very weak banking system and limits on private or public enterprise to access credit by frequently make it virtually non-functional. Controlling credit risk and acting in relation to arrears is necessary but if - as in Tete
}

not administrable. Within one to three years credit purchases of seed/tools, etc. should be via local commercial enterprises. That is a function they often can perform if they themselves have access to commercial credit.

User fees, as a source of revenue, fall in the same pragmatic means box. Total proposed charges need to be related to total probable household cash incomes and the practicality/cost thought out in advance with effective exemption procedures to guarantee access to absolutely poor people. If 90 per cent will need to be exempted and the rest charged $\$ 0.20$, then rural primary health care fees will be remarkably personnel-intensive and net revenue inefficient (probably negative). User participation is a different and broader issue. It is harder to develop, especially because administrators and professionals are not used to taking service users' views seriously or delegating operational roles to them, but potentially more useful (cf. Green 1993d).

Vehicle and working capital loans to the rural commercial network (on commercial terms) a re a priority because that network is vital to household livelihood restoration and in some cases (notably Mozambique) to urban food supply, the manufactured goods market, exports and the restoration of the indirect tax base. Rural commerce is best handled by private (including coop) enterprise. Wholesalers may need to be mixed if private capacity is low (e.g. even by 1989, Ghana had no wholesalers able to make year contracts or monthly grain, sugar or vegetable oil deliveries) and a floor price buyer of last resort (with actual capacity to buy) mechanism is often necessary to ensure competition/fair trading. ${ }^{11}$

The state should concentrate on doing what no one else can or will do, including enabling enterprises to do more (e.g. provide term credit for vehicles). It should not go in for Stalin Planning, e.g. providing donor-set, standard, stock-in-kind loans to rural retailers, instead of bank credit for them to buy what they believe to be appropriate stock - a route a bilateral aid agency, as well as foreign NGOs and, almost incredibly, the World Bank have advocated in Mozambique. 'Incentive goods' usually 30 to 50 lines in rural areas (e.g. Tanzanian

Province in 1993/94 - it brings virtually all private, co-op, public enterprise crop purchasing to a near halt for most of the main harvest/immediate post harvest season, that is an unacceptable result. 
unpublished early 1980s surveys) - are crucial, but rural merchants in daily contact with customers can determine products and quantities better than anyone else.

Rehabilitation programming, to be efficient, needs to be user coordinated (including not only beneficiaries but the field level staff who need to be able to implement it) and rapidly flexible. At the same time, it is unlikely to be effective at macrolevel unless there is a national conceptual and coordinating (including timely data consolidation and framework exchange) under afflicted-country leadership.

Local and intermediate level implementation is desirable - especially by user groups, domestic social sector bodies and local government units, as well as by foreign NGOs working with and, so far as possible, accountable to them. In the absence of such a context, parallel, anarchically autonomous interventions fragment and decapacitate, waste resources and create a crazy quilt of small, weak domestic user versus large, powerful external (including NGO) provider/decider relationships.

How to articulate is a contextual issue - e.g. how to build village and local roads. So too are the issues of relating to parallel programmes outside the rehabilitation core - e.g. ongoing vaccination, mother and child care basic health services in rural Mozambique as well as responses (presumably primarily via Provincial Calamities Commissions) to calamities such as drought. Conceptually these are 'part of rehabilitation' but - except for labour intensive infrastructure reconstruction - operationally they should be integral parts of health service structures (from National through District levels) from the start. $^{12}$

Assuming planning is decentralized, relationships are also needed with other special enabling programmes which may or may not be a formal part of rehabilitation ${ }^{13}$ : the 'Iringa Model', community (usually women's group)-based; district health/agriculture-assisted; locally-chosen, complementary

\footnotetext{
12. This is crucial because rehabilitation is a finite strategic initiative which rebuilds certain activities for permanent operation. The sooner these are located in and seen as ours by permanent institutions the better. One problem of links to external NGOs is that they, unlike domestic social sector bodies, seek to come in, set up, hand over with a depressing lack of strategic planning on how and when the last will be practicable, consistent with survival of the project or programme content.
}

activities for nutrition or child-care; a National Nutrition Council and UNICEF backed and coordinated approach (UNICEF 1994) would be an example if a variant were adopted in Mozambique. It could hardly be an across the board part of formal rehabilitation, however, as Tanzanian experience suggests most initial local programmes would be in less affected Districts or those in which rehabilitation was well advanced.

\section{CONCLUSION}

Given Mozambique's limited personnel, institutional capacity and finance its achievements can be asserted to be non-trivial. But over 1992-1994 probably $5,000,000$ to $5,500,000$ out of $7,000,000$ refugees, dislocated persons and pauperized in place household have returned home: the attempt to have a programme in being to meet and to support them has failed. The same holds true in Ethiopia and Eritrea and - in the absence of substantial breakthroughs - will hold true for Liberia, the Sahara Democratic Republic, the Sudan, Somalia (see Green 1993c), and Angola when they enter into post catastrophe contexts. The acceptance of rehabilitation as the centre piece of poverty reduction and - in Mozambique - of output and food security restoration is not yet achieved, much less acted upon.

If this presentation looks unlike most received wisdom and analysis (though, except perhaps in total coverage, it is not unique) then it is worth recalling who has forged that conventional wisdom and done the bulk of that analysis. Certainly not potential programme users nor persons trying to respond to their stated preferences and usually not afflicted country nationals at all. ${ }^{14}$ And then to reflect on the Africa proverb 'Until the lions have their historians, tales of hunting will always glorify the hunter'.

\section{See following page for references.}

\footnotetext{
${ }^{13}$ Presentation for financial mobilisation - domestic budget or donor - is a different issue. If a programme or part of a programme is a priority to make rehabilitation effective, seeking funding under that rubric is appropriate. That is - or should be - without prejudice to implementational modalities.

14 The Centre for Refugee Studies at Oxford has repeatedly stressed this point. See, e.g., Barbara Harrell-Bond, Imposing Ait, Oxford University Press, 1986.
} 


\section{REFERENCES}

\section{AND PUBLISHED/SEMI-PUBLISHED SOURCES}

Government of Mozambique, 1994, 'Poverty reduction strategy' (tentative title), Poverty Alleviation Unit, National Directorate of Planning, Maputo

1992a, Reconstrucao: The Road from Emergencia to Developmento - Livelihoods and Macroeconomics, National Planning Commission, June

1992b, National Reconstruction Programme, National Planning Commission, Maputo

1991, 'Poverty in Mozambique', Consultancy Report,

English version

Green, R. H., 1994, "The course of the four horsemen: the cost of war and its aftermath in sub-Saharan Africa' in J. Macrae et al. (eds), War and Hunger, London/New York: Zed Books

1993a, 'The political economy of drought in Southern Africa 1991-1993', Health Policy and Planning, Vol 8 No 3, Oxford: Oxford University Press: 255-266 1993b, 'Calamities and catastrophes: extending the UN Response', Third World Quarterly, Vol 14 No 1

1993c, 'Somalia: toward 1994-96 reconstruction rehabilitation and restructuring', Xerox, UNICEF-Somalia

1993d, 'Better health for Africans? Reflections on the World Bank present prospecti', paper for World Council of Churches 'Better Health in Africa' conference, October 2021, Geneva

Hanlon, J., 1991, Mozambique: Who Calls The Shots, London: James Currey

UNICEF, 1994, We Shall Never Go Back, Dar es Salaam/ New York

1992, Signs of Hope: Towards Rehabilitation and Renewed Development for the Children of Southern Africa, Windhoek (Regional Economic Policy Unit)

1989, Children On The Front Line: The impact of apartheid, destabilization and warfare on children in southern and South Africa (third edition), New York 